\title{
GLIPR1- $\Delta$ TM synergizes with docetaxel in cell death and suppresses resistance to docetaxel in prostate cancer cells
}

Styliani Karanika ${ }^{1 \dagger}$, Theodoros Karantanos ${ }^{1 \dagger}$, Shinji Kurosaka ${ }^{2 \dagger}$, Jianxiang Wang ${ }^{1}$, Takahiro Hirayama ${ }^{2}$, Guang Yang ${ }^{1}$, Sanghee Park' Alexei A. Golstov ${ }^{3}$, Ryuta Tanimoto ${ }^{4}$, Likun Li ${ }^{1}$ and Timothy C. Thompson ${ }^{1 *}$

\begin{abstract}
Background: Docetaxel is the first chemotherapy agent approved for treatment of metastatic castration-resistant prostate cancer ( $\mathrm{mCRPC}$ ). The limited survival benefit associated with the quick emergence of resistance and systemic toxicity diminished its efficacy. JNK-mediated apoptosis is one of the mechanisms of docetaxel activity whereas ERK1/2-c-Myc-CXCR4 signaling is implicated in the development of resistance and induction of migration. The aim of this study was to evaluate the hypothesis that the combination treatment with docetaxel and GLIPR1- $\Delta$ TM will synergistically induce greater cell death and inhibit the emergence of resistance and development of metastatic potential in prostate cancer (PCa) cells.

Methods: The synergistic effects of the docetaxel and GLIPR1- $\Delta$ TM were evaluated with DNA fragmentation, DAPI staining and MTS using paired $t$-test and isobologram study. The effects of the drugs on JNK and ERK1/2-c-Myc-CXCR4 signaling were evaluated with Western blot, DNA fragmentation, and MTS assays using the JNK inhibitor SP600125, and CXCR4 siRNA. The results of docetaxel and GLIPR1- $\triangle$ TM combination on migration were examined with scratch assay using the CXCR4 inhibitor AMD3100 while our hypothesis was examined in vivo using VCaP orthotopic xenograft model.

Results: We found that GLIPR1- $\triangle$ TM synergized with docetaxel to induce apoptosis in VCaP and PC-3 PCa cells through induction of JNK signaling and concomitant inhibition of ERK1/2-C-Myc-CXCR4 signaling. We showed that JNK activation mediates the apoptotic effects of the drug combination and that CXCR4 knockdown increases its efficacy. We also found that the addition of GLIPR1- $\Delta$ TM to docetaxel decreases the migration of VCaP and PC-3 cells. The combination treatment with docetaxel and GLIPR1- $\triangle$ TM inhibited tumor growth and decreased metastatic potential in VCaP xenografts more than single agents did.
\end{abstract}

Conclusions: Our data suggested that addition of GLIPR1- $\triangle$ TM treatment in PCa cells increases the efficacy of docetaxel and may inhibit the emergence of drug resistance; potentially permitting a decrease of docetaxel dose for patients with mCRPC eliminating its systemic toxicities.

Keywords: Prostate cancer, GLIPR1-ATM, Docetaxel, JNK, ERK1/2, c-Myc, CXCR4, Combination treatment

\footnotetext{
* Correspondence: timthomp@mdanderson.org

${ }^{\dagger}$ Equal contributors

'Department of Genitourinary Medical Oncology - Research, Unit 18-3, The University of Texas MD Anderson Cancer Center, 1515 Holcombe Boulevard, Houston, TX, USA

Full list of author information is available at the end of the article
}

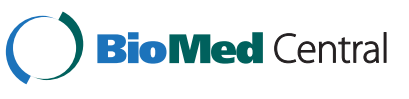

(c) 2015 Karanika et al. This is an Open Access article distributed under the terms of the Creative Commons Attribution License (http://creativecommons.org/licenses/by/4.0), which permits unrestricted use, distribution, and reproduction in any medium, provided the original work is properly credited. The Creative Commons Public Domain Dedication waiver (http://creativecommons.org/publicdomain/zero/1.0/) applies to the data made available in this article, unless otherwise stated. 


\section{Background}

The survival of patients with metastatic castrationresistant prostate cancer (mCRPC) remains poor despite the introduction of novel antiandrogens such as enzalutamide and abiraterone $[1,2]$. Taxanes, in particular docetaxel and cabazitaxel, are the only chemotherapy agents that have been shown to increase survival in mCRPC patients $[3,4]$ and recent evidence suggests that these agents are particularly effective in patients with high Gleason score primary disease [5].

Despite the long period of docetaxel use, the exact mechanism(s) of its function is not well-understood. Docetaxel is believed to stabilize microtubules by arresting their de-polymerization, leading to disruption of normal mitosis, G2/M arrest, and inhibition of cell proliferation [6]. This agent inhibits Bcl-2 and Bcl-xL activity through decreased gene expression and posttranslational phosphorylation, promoting apoptosis in PCa cells [6-8]. In melanoma cells, docetaxel induces apoptosis through activation of the c-Jun NH2-terminal kinase (JNK) pathway, but it also activates the ERK1/2 (Extracellular signal-regulated kinase 1/2) signaling which seems to inhibit its apoptotic effects [9]. In addition, docetaxel increases reactive oxygen species (ROS) production, which promotes JNK activation in androgen receptor (AR)- negative PCa cells [10]. Collectively, these data suggest that docetaxel promotes cancer cell death through apoptosis mediated by JNK activation.

Even when $\mathrm{mCRPC}$ initially responds to treatment with docetaxel, the disease eventually becomes resistant, which can be attributed to numerous molecular mechanisms according to recent studies in different types of cancer. Mhaidat et al. demonstrated that in melanoma cells treated with docetaxel, activation of PKC $\delta$ is associated with proapoptotic responses through JNK activation, as mentioned above, while activation of $\mathrm{PKC} \varepsilon$ enhances prosurvival signaling through ERK1/2 activation [11]. These results indicate that under docetaxel treatment, one pathway downstream of PKC may lead to apoptosis and another associated with ERK signaling may lead to cell survival and resistance to docetaxel. Of note, multiple recent reports demonstrated opposed effects and negative crosstalk between JNK and ERK1/2 signaling [12-15], suggesting that ERK1/2 activation by docetaxel may inhibit its JNK-mediated apoptotic effects. Leonetti et al. found that treatment combining docetaxel with antisense oligodeoxynucleotides against $\mathrm{Bcl}-2$ and c-Myc led to lower PC-3 cell survival in vitro, and had higher antitumor efficacy in PC-3 xenografts, than did docetaxel alone, suggesting that $\mathrm{Bcl}-2$ and $\mathrm{c}-\mathrm{Myc}$ upregulation may promote resistance to docetaxel as well [16]. Finally, a recent report showed that docetaxel induces the activation of ERK, which stabilizes c-Myc protein, and stimulates CXCR4 (C-X-C chemokine receptor type 4) signaling [17]. The same report showed that CXCR4 can, in turn, activate ERK1/2; these signaling activities establish a positive feedback resistance loop in response to docetaxel [17]. Overall, these findings support the concept that activation of ERK1/2-c-Myc-CXCR4 pathway can promote the development of resistance to docetaxel and potentially inhibit the JNK apoptotic signaling.

Recently, cabazitaxel was shown to be effective in patients who progressed under abiraterone and enzalutamide after failure of docetaxel suggesting that taxanes may still be a reasonable therapeutic approach for these patients [18]. The combination of docetaxel with a novel agent may be the most reasonable approach to increase the apoptotic effects of docetaxel and delay or inhibit the development of resistance. Such combination therapy also has the potential to reduce effective doses of docetaxel, thereby decreasing the incidence of docetaxel side effects such as myelosuppression [19]. Numerous studies failed to show improvement of docetaxel efficacy when it was combined with other targeted agents such as dasatinib and zibotentan [20, 21].

The gene encoding the human glioma pathogenesisrelated protein 1 (GLIPR1), a p53 target, is downregulated in PCa due to methylation of its promoter [22, 23]. Li et al. demonstrated that GLIPR1 upregulation leads to accumulation of ROS and subsequent activation of the JNK pathway and downregulation of Bcl-2 [24]. GLIPR1 was also found to be associated with destablizing phosphorylation of $\beta$ catenin and c-Myc, leading to their degradation [25]. Our group recently showed that GLIPR $1-\Delta \mathrm{TM}$ is selectively taken up by PCa cells; activates apoptosis through ROS accumulation; and downregulates c-Myc [26]. Collectively, these results indicate that GLIPR1- $\triangle \mathrm{TM}$ may be a good candidate for combination therapy with docetaxel, since it promotes PCa specific cell death through JNK activation, whereas it downregulates c-Myc signaling which has been extensively associated with the emergence of resistance to docetaxel through ERK1/2-c-Myc-CXCR4 signaling.

In the current study, we report that GLIPR1- $\triangle \mathrm{TM}$ increases the sensitivity of PCa cells to docetaxel in a synergistic way through additive induction of JNK-mediated apoptosis in VCaP and PC-3 cells and concurrent inhibition of ERK1/2-c-Myc-CXCR4-mediated development of resistance. The addition of GLIPR1- $\triangle \mathrm{TM}$ to docetaxel was found to decrease the migration of PCa cells while this combination additively decreased tumor growth and metastatic potential in $\mathrm{VCaP}$ xenografts.

\section{Results}

\section{GLIPR1- $\triangle$ TM and docetaxel synergistically decreased} survival of VCaP and PC-3 cells in vitro

To test the hypothesis that GLIPR1- $\triangle \mathrm{TM}$ sensitizes PCa cells to docetaxel, we used VCaP cells and PC-3 cells. Both cell lines were derived from bone metastases of 
PCa. VCaP cells were derived from a patient with mCRPC, while PC-3 cells are androgen receptor-negative metastatic PCa cells. We also included RWPE-1 cells, which are epithelial cells derived from the peripheral zone of an histologically normal adult human prostate and transfected with a single copy of human papillomavirus 18 [26]. The three cell lines were treated for $48 \mathrm{~h}$ with various concentrations of docetaxel $(0.5,1,2,5,10,20,50,75$, and $100 \mathrm{nM})$ and GLIPR1- $\Delta$ TM $(1,2,5,10,20,40,80$,and $160 \mu \mathrm{g} / \mathrm{ml})$ in different serum concentrations $(0.1 \%$ for PC-3 cells and $0.5 \%$ for VCaP and RWPE-1 cells), and MTS assay was performed to evaluate the dose response and the IC50 for each single-agent treatment. At a concentration of $0.5 \mathrm{nM}$, docetaxel resulted in significantly lower survival of both PCa cell lines ( $p=0.004$ for VCaP cells, $p=0.03$ for PC-3 cells) than did the control treatment (Fig. 1a). The IC50 was $69.8 \mathrm{nM}$ for $\mathrm{VCaP}$ cells and $70.5 \mathrm{nM}$ for $\mathrm{PC}-3$ cells.
Docetaxel significantly decreased survival of normal prostate cells (RWPE- 1 ) even at the lowest $(0.5 \mathrm{nM})$ concentration $(p<0.0001)$ (Fig. 1a). At $2.5 \mu \mathrm{g} / \mathrm{ml}$ GLIPR1- $\Delta$ TM resulted in significantly decreased survival of $\mathrm{VCaP}$ cells $(p=0.002)$, and at $10 \mu \mathrm{g} / \mathrm{ml}$ resulted in significantly decreased survival of PC-3 cells $(p=0.0005)$ compared to control treatment (Fig. 1b). The IC50 was $34.8 \mu \mathrm{g} / \mathrm{ml}$ for $\mathrm{VCaP}$ cells and $154 \mu \mathrm{g} / \mathrm{ml}$ for PC-3 cells. Interestingly, only $160 \mu \mathrm{g} / \mathrm{ml}$ GLIPR1- $\Delta$ TM decreased survival of normal prostate cells (RWPE-1) $(p=0.002)$ (Fig. 1b), which is consistent with our previous results [25] showing that GLIPR1- $\triangle \mathrm{TM}$ is selectively taken up by cancerous cells, promoting their apoptosis, while normal prostate cells are not sensitive to this agent.

To investigate the potential synergy of docetaxel and GLIPR1- $\triangle \mathrm{TM}$ in inducing anti-cancer effects, we treated $\mathrm{VCaP}$ and PC-3 cells with various combinations of the
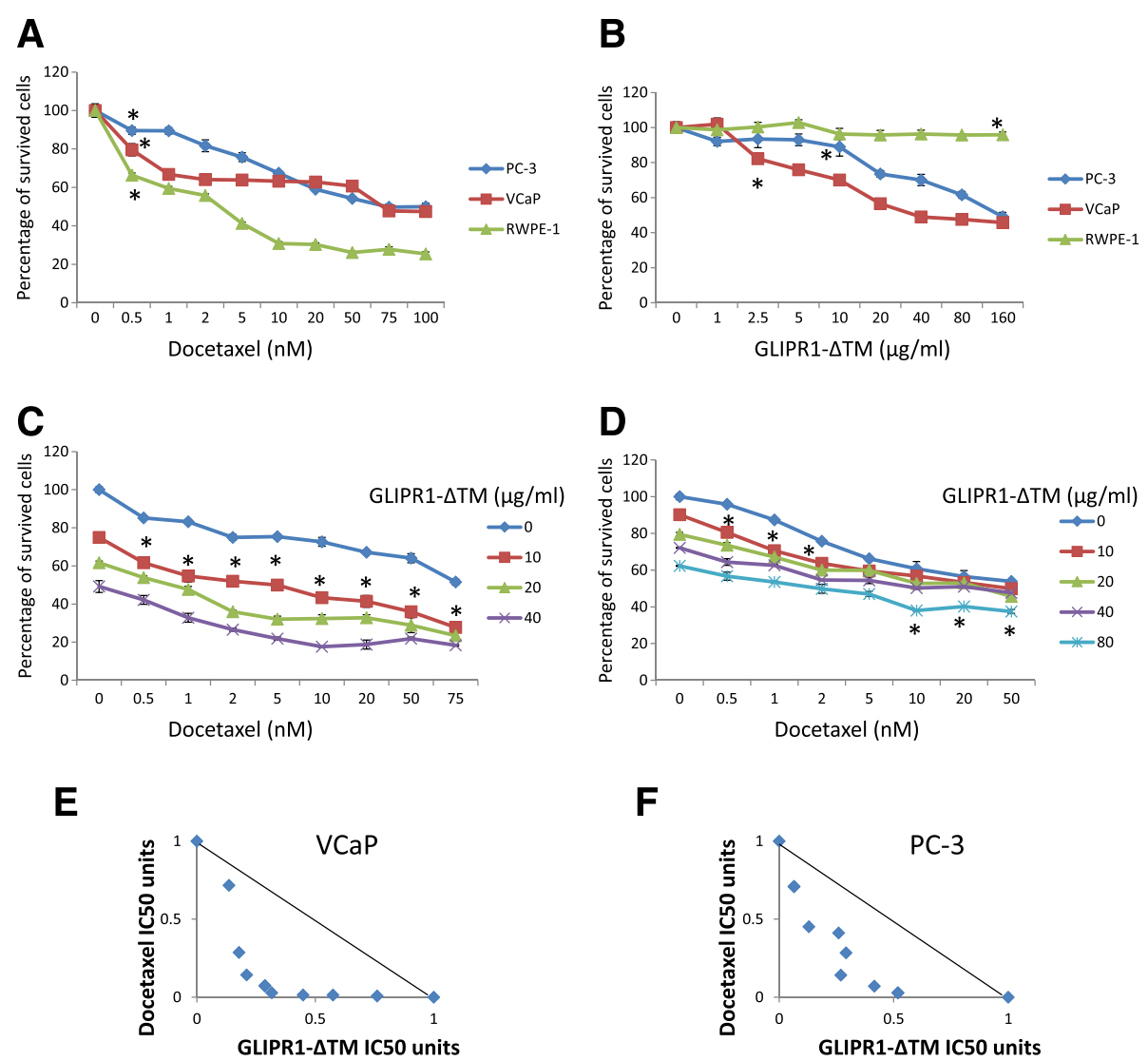

Fig. 1 GLIPR1- $\triangle$ TM reduced VCaP and PC-3 cells' survival synergistically with docetaxel. a. Docetaxel dose-response curves of VCaP, PC-3, and RWPE-1 cells treated for $48 \mathrm{~h}$, determined using MTS assay. At $0.5 \mathrm{nM}$, docetaxel significantly decreased cell survival in the three cell lines. The IC50 was $69.8 \mathrm{nM}$ for VCaP cells and 70.5nM for PC-3 cells. b. GLIPR1- $\triangle T$ M dose-response curves of VCaP, PC-3, and RWPE-1 cells treated for 48 h, determined using MTS assay. At $2.5 \mu \mathrm{g} / \mathrm{ml}$ and $10 \mu \mathrm{g} / \mathrm{ml}$, GLIPR1- $\Delta$ TM significantly decreased survival of VCaP and PC-3 cells, respectively. Only $160 \mu \mathrm{g} / \mathrm{ml}$ decreased survival of RWPE-1 cells. The IC50 was $34.8 \mu \mathrm{g} / \mathrm{ml}$ for VCaP cells and $154 \mu \mathrm{g} / \mathrm{ml}$ for PC-3 cells. c. The addition of $10 \mu \mathrm{g} / \mathrm{ml}$ GLIPR1- $\triangle$ TM increased the efficacies of all doses of docetaxel in inhibiting VCaP cells' survival, based on MTS assay. $\mathbf{d}$. The addition of $10 \mu \mathrm{mg} / \mathrm{ml}$ GLIPR1- $\Delta$ TM increased the efficacies of $0.5,1$, and $2 \mathrm{nM}$ docetaxel in inhibiting PC-3 cells' survival as determined by MTS assay, and the addition of $80 \mathrm{\mu g} / \mathrm{ml}$ GLIPR1- $\Delta$ TM increased the efficacies of 10, 20, and 50nM docetaxel. e. Isobologram analysis showed that GLIPR1- $\Delta$ TM and docetaxel synergistically induced cell death in VCaP cells. f. Isobologram analysis showed that GLIPR1- $\triangle T M$ and docetaxel induced cell death synergistically in PC-3 cells. The results are presented as the mean \pm standard error from at least three independent experiments 
two agents: $0.5,1,2,5,10,20,50$, and $75 \mathrm{nM}$ docetaxel in both cell lines; $0,10,20$, and $40 \mu \mathrm{g} / \mathrm{ml}$ GLIPR1- $\Delta \mathrm{TM}$ in VCaP cells; and $0,10,20,40$, and $80 \mu \mathrm{g} / \mathrm{ml}$ GLIPR1- $\Delta \mathrm{TM}$ in PC-3 cells. At $10 \mu \mathrm{g} / \mathrm{ml}$, GLIPR1- $\Delta$ TM significantly increased the efficacy of docetaxel in $\mathrm{VCaP}$ cells at all docetaxel doses (Fig. 1c) and significantly increased the efficacy of docetaxel at $0.5,1$, and $2 \mathrm{nM}$ docetaxel in PC-3 cells (Fig. 1d). At $80 \mu \mathrm{g} / \mathrm{ml}$, GLIPR1- $\Delta$ TM significantly increased the efficacy of higher doses of docetaxel (10, 20, and 50nM) (Fig. 1d).

To evaluate whether the effects of combination treatments on survival were super-additive (synergistic), $50 \%$ of maximum efficacy was used to determine the fixed ratio, and multiple combination doses with the same efficacy were included. Isobologram analysis showed that the effects were synergistic (Fig. 1e, f).

\section{GLIPR1- $\Delta$ TM increased the apoptotic effect of docetaxel in VCaP and PC-3 cells}

Given the known apoptotic effects of GLIPR1- $\Delta$ TM and docetaxel in PCa cells, we hypothesized that the decreased survival of PCa cells treated with combinations of these two agents is mainly due to increased apoptosis. To test this hypothesis, we used DAPI staining and DNA fragmentation assay to examine apoptosis in $\mathrm{VCaP}$ and $\mathrm{PC}-3$ cells. We included RWPE-1 cells as a control. VCaP and RWPE-1 cells were treated with $0.5 \%$ serum-containing medium for $24 \mathrm{~h}$, and PC-3 cells were treated with $0.1 \%$ serumcontaining medium for $24 \mathrm{~h}$. Then, cells were treated with various concentrations of GLIPR1- $\Delta \mathrm{TM}(0,10$, 20 , and $40 \mu \mathrm{g} / \mathrm{ml}$ ) for $1 \mathrm{~h}$ followed by addition of various concentrations of docetaxel $(0,0.5,1,2,5$, and $10 \mathrm{nM}$ ). Forty-eight hours later, DAPI staining was evaluated. At $10 \mu \mathrm{g} / \mathrm{ml}$, GLIPR1- $\Delta \mathrm{TM}$ in combination with all docetaxel concentrations significantly increased the percentage of apoptotic VCaP cells $(p<0.001)$ (Fig. 2a). In PC-3 cells, $10 \mu \mathrm{g} / \mathrm{ml}$ GLIPR1- $\Delta \mathrm{TM}$ significantly increased the apoptotic effects of $0.5 \mathrm{nM}(p=0.014)$ and $10 \mathrm{nM}(p=0.033)$ docetaxel, while $20 \mu \mathrm{g} / \mathrm{ml}$ GLIPR1- $\Delta \mathrm{TM}$ significantly increased the apoptosis induced by $1 \mathrm{nM}$ docetaxel $(p=0.016)$ and $40 \mu \mathrm{g} / \mathrm{ml} \mathrm{GLIPR1- \Delta TM}$ increased the apoptotic effect of $2 \mathrm{nM}$ docetaxel ( $p=0.0095)$ (Fig. 2b). In RWPE-1 cells, GLIPR1- $\Delta \mathrm{TM}$ did not increase the apoptosis induced by any dose of docetaxel, which is consistent with the results of the cell survival assay and our previous data showing that GLIPR1- $\Delta$ TM selectively induces apoptosis in PCa cells but not in normal prostate cells. In RWPE-1 cells, $1 \mathrm{nM}$ docetaxel induced apoptosis $(p=0.0025)$ (Fig. 2c).

According to DNA fragmentation assay, $10 \mu \mathrm{g} / \mathrm{ml}$ GLIPR1- $\triangle \mathrm{TM}$ in combination with all docetaxel doses increased apoptosis in VCaP cells $(p=0.0014$ for $0.5,1$, and $2 \mathrm{nM}$ docetaxel; $p=0.0028$ for $5 \mathrm{nM}$ docetaxel; $p=0.0012$ for $10 \mathrm{nM}$ docetaxel) (Fig. 2d). In PC-3 cells, $10 \mu \mathrm{g} / \mathrm{ml}$ GLIPR1- $\Delta$ TM enhanced the apoptotic effects of all doses of docetaxel ( $p=0.001$ for $0.5 \mathrm{nM}$ docetaxel; $p<0.001$ for 1 , 2, 5, and 10nM docetaxel) (Fig. 2e). GLIPR1- $\Delta$ TM did not increase the apoptotic effects of any docetaxel doses in RWPE- 1 cells, in which $0.5 \mathrm{nM}$ docetaxel induced apoptosis $(p=0.0094)$ (Fig. 2f). Collectively, these results demonstrated that GLIPR1- $\Delta$ TM enhanced the apoptotic activity of docetaxel in VCaP and PC-3 PCa cells without substantially affecting normal prostate cells.

\section{Combination treatment with docetaxel and GLIPR1- $\triangle T$ M induced JNK signaling and inhibited the docetaxel-induced ERK1/2-c-Myc-CXCR4 signaling resistance loop, increasing apoptosis through maximal JNK activation}

We have previously demonstrated that endogenous GLIPR1 activates JNK signaling [22] and docetaxel was also found to induce JNK signaling and subsequent apoptosis in melanoma cells [9]. Initially, we hypothesized that the greater apoptotic effect of the combination of these two agents is mediated by JNK activation and inhibition of ERK1/2-c-Myc-CXCR4 signaling by GLIPR1- $\Delta$ TM. To test this hypothesis, we initially examined the effect of combination treatment on JNK and ERK1/2-c-Myc-CXCR4 signaling. To select the right time-point for this evaluation during treatment using the lowest effective doses, we examined survival of $\mathrm{VCaP}$ and $\mathrm{PC}-3$ cells treated with 1,2 , or $5 \mathrm{nM}$ docetaxel or 10,20 , or $40 \mu \mathrm{g} / \mathrm{ml}$ GLIPR1- $\triangle T M$. The time-response curves were different in $\mathrm{VCaP}$ and PC-3 cells. In particular, $1 \mathrm{nM}$ docetaxel and $10 \mu \mathrm{g} / \mathrm{ml}$ GLIPR1- $\Delta \mathrm{TM}$ significantly decreased the survival of VCaP cells at $24 \mathrm{~h}(p=0.03$ for docetaxel and $p=0.001$ for GLIPR1- $\Delta$ TM) (Fig. 3a) and the survival of PC-3 cells at $48 \mathrm{~h}(p<0.001$ for docetaxel and $p=0.007$ for GLIPR1- $\Delta \mathrm{TM}$ ) (Fig. $3 \mathrm{~b}$ ).

We next investigated the effect of the combination of $1 \mathrm{nM}$ docetaxel and $10 \mu \mathrm{g} / \mathrm{ml} \mathrm{GLIPR} 1-\Delta \mathrm{TM}$ on JNK and ERK1/2-c-Myc-CXCR4 signaling at $24 \mathrm{~h}$ for $\mathrm{VCaP}$ cells and $48 \mathrm{~h}$ for PC-3 cells. In order to evaluate the role of JNK signaling in apoptosis and ERK1/2-c-Myc-CXCR4 loop, we included the JNK inhibitor SP600125 in these experiments, a known agent which acts through inhibiting JNK phosphorylation [27]. $\mathrm{VCaP}$ and PC-3 cells were treated with $0.5 \%$ or $0.1 \%$ serum-containing medium, respectively, for $24 \mathrm{~h}$. Then, cells were treated with $10 \mu \mathrm{g} / \mathrm{ml}$ GLIPR1- $\Delta$ TM for $1 \mathrm{~h}$ followed by addition of $1 \mathrm{nM}$ docetaxel with or without $1 \mu \mathrm{M}$ SP600125 for 24 or $48 \mathrm{~h}$. Western blot experiments were conducted at least three times and our results reflect at least three independent experiments. The quantitative data are presented as supplementary data (Additional file 1: Figure S1). Representative blots are presented in the Fig. 4. Combination treatment increased JNK phosphorylation in $\mathrm{VCaP}$ and PC-3 cells more than docetaxel or GLIPR1- $\Delta$ TM did 


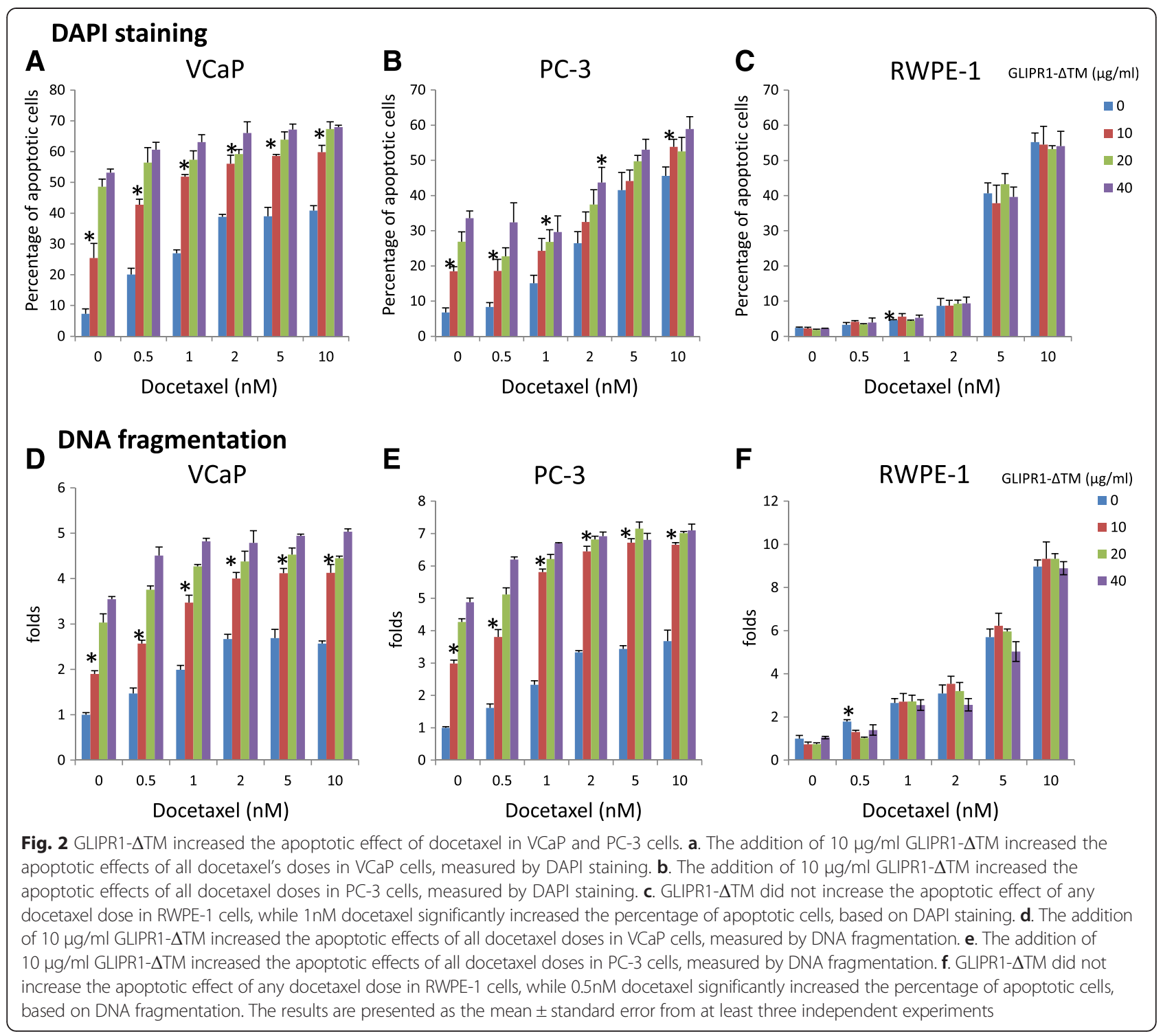

when used as single agents (Fig. 4a, b). Based on our Western blot data, docetaxel alone increased the ERK1/2 phosphorylation (modestly in VCaP cells), and c-Myc and CXCR4 protein levels whereas the combination treatment reduced ERK1/2 phosphorylation and c-Myc and CXCR4 protein levels in both cell lines. In contrast, the addition of SP600125 to the combination treatment increased ERK1/2 phosphorylation and protein levels of c-Myc and CXCR4 (Fig. 4a, b).

To further test our hypothesis that JNK mediates the apoptotic effects of docetaxel and GLIPR1- $\Delta$ TM combination treatment, we treated $\mathrm{VCaP}$ and $\mathrm{PC}-3$ cells with DMSO, docetaxel, GLIPR1- $\triangle \mathrm{TM}$ or combination treatment with or without JNK inhibitor, SP600125, and performed MTS and DNA fragmentation assays to evaluate survival and apoptosis, respectively. We found that the percentage of survived $\mathrm{VCaP}$ and $\mathrm{PC}-3$ cells treated with the combination of docetaxel and GLIPR1- $\triangle \mathrm{TM}$ was significantly increased when SP600125 was added $(p<0.001$ for both cell lines) according to MTS assay. Additionally, in PC-3 cells, we also found that the addition of SP600125 increased the survival when added to docetaxel $(p=0.048)$ which is consistent with the JNK-mediated apoptotic effect of docetaxel. Through DNA fragmentation assay, we found that the addition of SP600125 decreased the apoptotic effect of docetaxel $(p<0.001$ for $\mathrm{VCaP}$ and PC-3 cells), GLIPR1- $\Delta$ TM $(p<0.001$ for VCaP cells and $p=0.002$ for PC-3 cells) and combination therapy $(p<0.001$ for $\mathrm{VCaP}$ and PC-3 cells). Collectively, these data suggested that docetaxel and GLIPR1- $\triangle$ TM combination treatment synergistically increased apoptosis by maximal activation of JNK, together with suppression of ERK1/2 signaling, which further increased JNK signaling through a derepression mechanism. Finally, the 

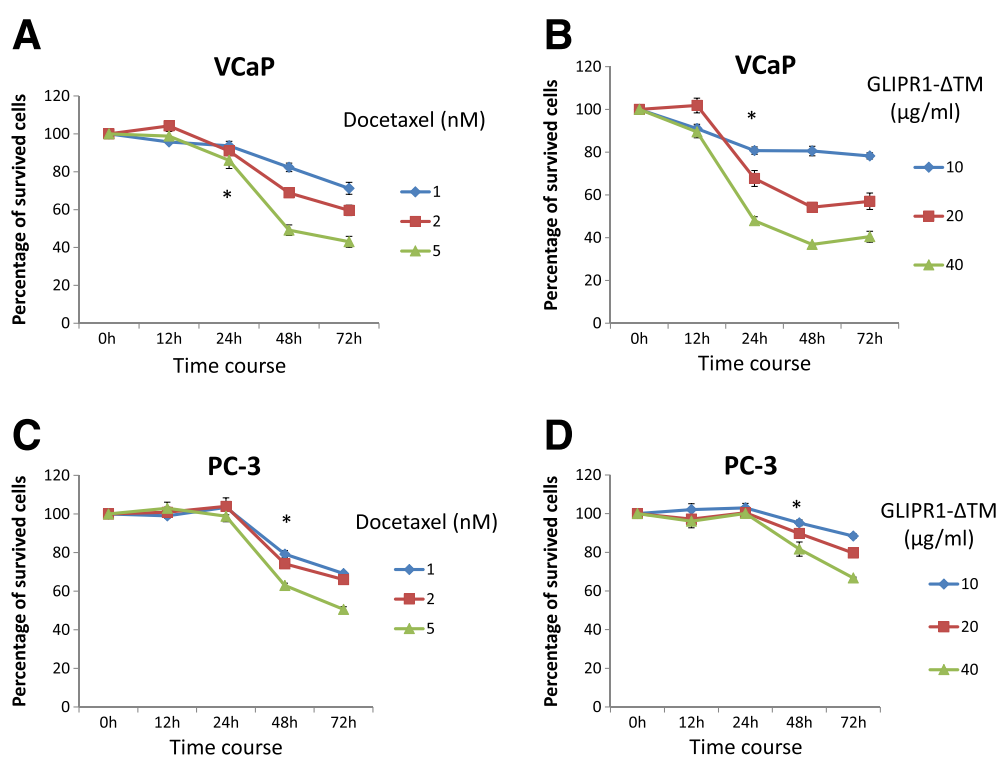

Fig. 3 Time-dependent curves of docetaxel and GLIPR1- $\Delta$ TM efficacies in VCaP and PC-3 cells treated with 1, 2, or 5nM docetaxel or 10, 20, or $40 \mu \mathrm{g} / \mathrm{ml}$ GLIPR1- $\Delta$ TM. a,b. $1 \mathrm{nM}$ docetaxel and $10 \mu \mathrm{g} / \mathrm{ml}$ GLIPR1- $\Delta$ TM significantly decreased survival of VCaP cells at $24 \mathrm{~h}$ ( $p=0.03$ for docetaxel and $p=0.001$ for GLIPR1- $\Delta$ TM). $\mathbf{c}$ d. Time-dependent curves of docetaxel and GLIPR1- $\Delta$ TM efficacies in PC-3 cells treated with 1, 2, or $5 \mathrm{nM}$ docetaxel or 10,20 , or $40 \mu \mathrm{g} / \mathrm{ml}$ GLIPR1- $\Delta$ TM showed that $1 \mathrm{nM}$ docetaxel and $10 \mu \mathrm{g} / \mathrm{ml}$ GLIPR1- $\Delta$ TM significantly decreased survival of these cells at $48 \mathrm{~h}$ ( $p<0.001$ for docetaxel and $p=0.007$ for GLIPR1- $\Delta$ TM). The results are presented as the mean \pm standard error from at least three independent experiments

ERK1/2-c-Myc-CXCR4 docetaxel-induced resistance loop [17], was downregulated by the drug combination which led to reduced migration activity.

\section{CXCR4 knockdown potentiated the apoptotic effects of docetaxel and the combination treatment with docetaxel and GLIPR1- $\triangle T$ M decreased the migration of VCaP and PC-3 cells}

We showed that the addition of GLIPR1- $\triangle \mathrm{TM}$ decreased the docetaxel-mediated ERK1/2-c-Myc-CXCR4 induction in VCaP and PC-3 cells. GLIPR1- $\triangle \mathrm{TM}$ was expected to further activate the apoptosis and inhibited the development of resistance through this pathway. We evaluated the effects of the CXCR4 downregulation on docetaxel and GLIPR1- $\triangle \mathrm{TM}$ treatment in terms of apoptosis and survival of $\mathrm{VCaP}$ and PC-3 cells. Thus, we treated $\mathrm{VCaP}$ and $\mathrm{PC}-3$ cells with CXCR4si7 and CXCR4si8 siRNAs for $48 \mathrm{~h}$ and found that the most effective siRNA in terms of downregulation of CXCR4 is the CXCR4si7. Consequently, we treated VCaP and PC3 cells with CXCR4si7 for $24 \mathrm{~h}$ and then treated them with GLIPR1- $\triangle \mathrm{TM}$ and docetaxel for 24 and $48 \mathrm{~h}$ as described above. Western blot experiments were conducted three times and the quantitative data are presented as supplementary data (Additional file 1: Figure S1). We evaluated the survival with MTS assay and apoptosis with DNA fragmentation assay. We found that the treatment with CXCR4si reduced the survival of cells treated with docetaxel $(p<0.001)$, GLIPR1- $\Delta$ TM $(p<0.001)$ and combination $(p=0.041)$ (Fig. $5 \mathrm{~b})$ in $\mathrm{VCaP}$ cells. According to DNA fragmentation assay, we found that knockdown of CXCR4 increased the apoptotic effect of docetaxel $(p<0.001)$, GLIPR1- $\triangle \mathrm{TM}(p<0.001)$ and combination $(p=0.01)$ in VCaP cells (Fig. $5 c)$. In PC-3 cells, we found that CXCR4 downregulation reduced the survival of cells treated with docetaxel $(p<0.001)$, GLIPR1- $\Delta$ TM $(p<0.001)$ and combination $(p<0.001)$ (Fig. $5 \mathrm{~d})$. According to DNA fragmentation assay, we found that CXCR4 knockdown increased the apoptotic effect of docetaxel $(p<0.001)$, GLIPR1- $\Delta \mathrm{TM}(p<0.001)$ and combination $(p<0.001)$ in PC-3 cells (Fig. 5e). These data suggested that CXCR4 downregulation further potentiated the apoptotic effect of each single agent and their combination as well, when was combined with them, confirming that the inhibition of the ERK1/2-c-Myc-CXCR4 resistance pathway led to increased apoptosis. In our proposed combination treatment, GLIPR1- $\triangle \mathrm{TM}$ worked as the key molecule which reduced CXCR4 levels through suppression of ERK1/2-c-Myc, and consequently maximally increased JNK-induced apoptotic signaling stimulated by docetaxel through ERK1/2 downregulation and JNK derepression. Given the known role of CXCR4 as an inducer of migration and metastasis in PCa [28], and based on our results that GLIPR1- $\triangle \mathrm{TM}$ inhibited the docetaxel-induced ERK1/2-c-Myc-CXCR4 signaling, we evaluated the hypothesis that the combination of GLIPR1- $\Delta \mathrm{TM}$ and docetaxel 


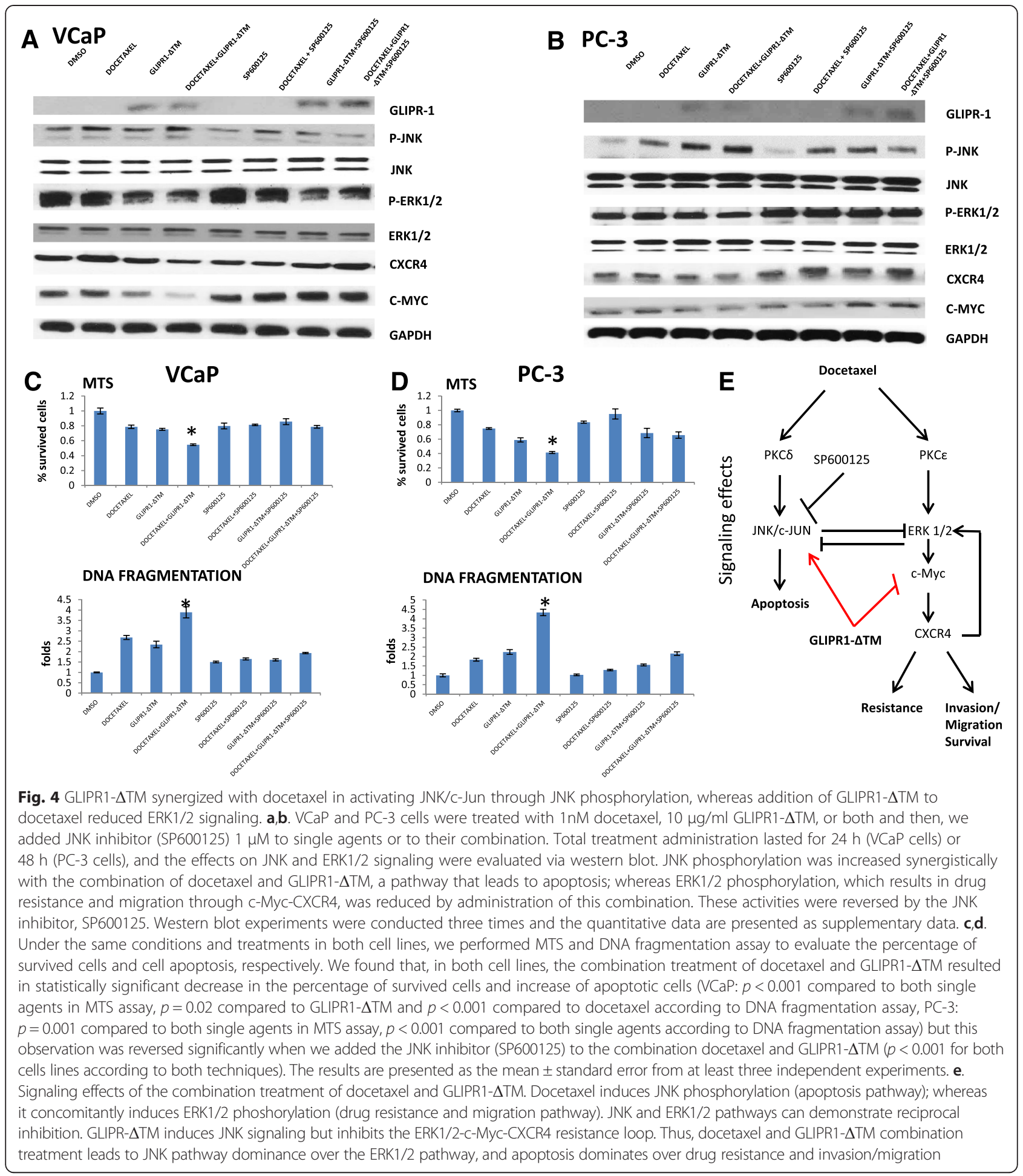

can inhibit migration of $\mathrm{VCaP}$ and $\mathrm{PC}-3$ cells more than docetaxel alone. We treated $\mathrm{VCaP}$ and $\mathrm{PC}-3$ cells with $0.5 \%$ or $0.1 \%$ serum-containing medium, respectively, followed by $1 \mathrm{nM}$ docetaxel, with or without the addition of $10 \mu \mathrm{g} / \mathrm{ml}$ GLIPR1- $\Delta$ TM hour before the initiation of docetaxel treatment. After $24 \mathrm{~h}$ cell migration was assessed by scratch assay. As a positive control, we used $25 \mu \mathrm{g} / \mathrm{ml}$ AMD3100, a CXCR4 inhibitor, as previously described [29]. The addition of GLIPR1- $\triangle \mathrm{TM}$ to docetaxel significantly decreased the number of migrated $\mathrm{VCaP}$ cells $(p<0.001)$ (Fig. 5f) and PC-3 cells $(p<0.001)$ than docetaxel alone did (Fig. 5g). 


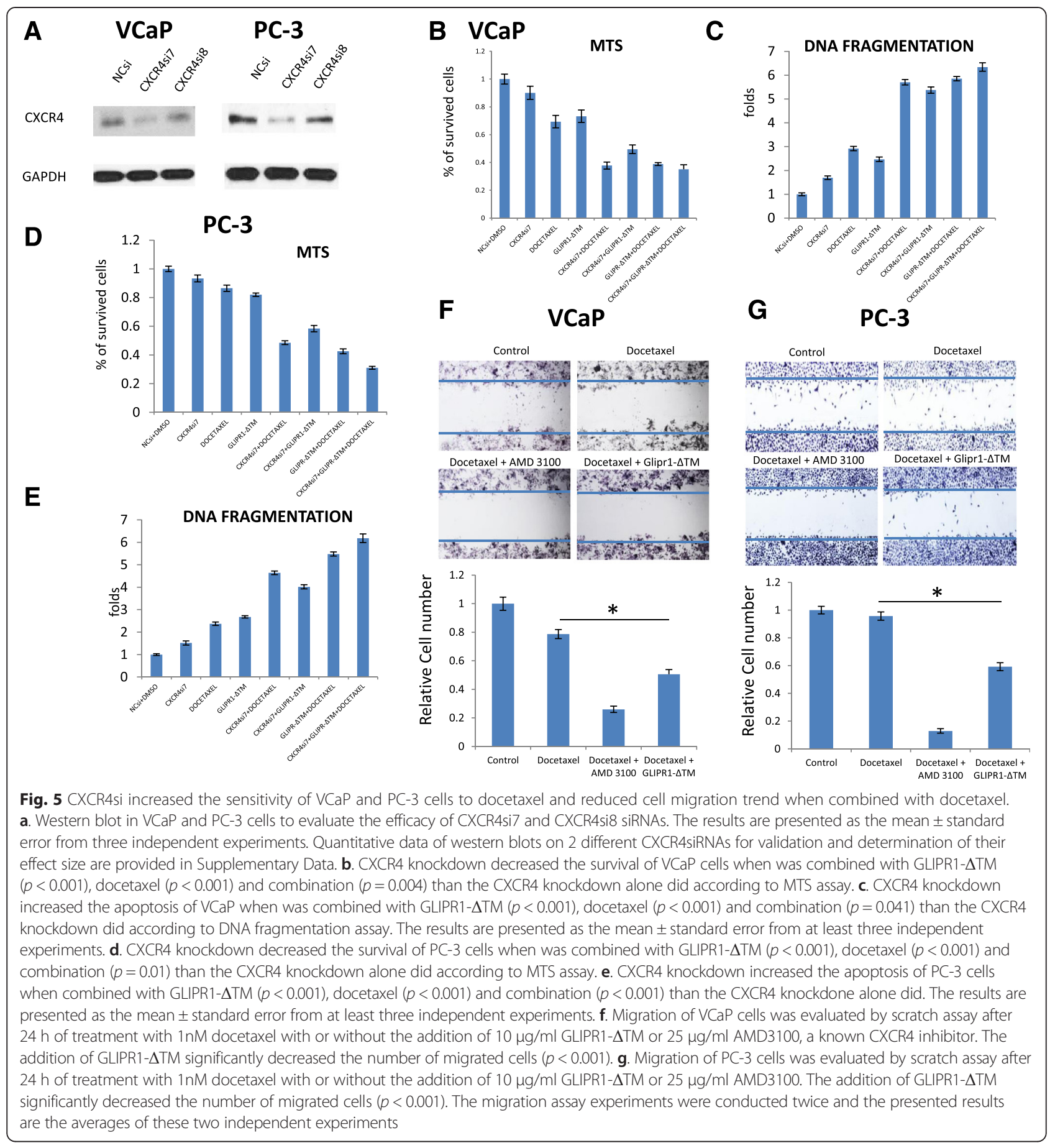

\section{Combination treatment with docetaxel and GLIPR- $\Delta$ TM inhibited growth and metastasis of VCaP othotopic xenografts}

To validate the efficacy of the combination of GLIPR1$\triangle \mathrm{TM}$ and docetaxel in vivo, we treated nude mice bearing $\mathrm{VCaP}$ orthotopic tumors with PBS (control), docetaxel alone, GLIPR1- $\triangle \mathrm{TM}$ alone, or the combination of these two agents. Three weeks after the initiation of treatment, combination treatment significantly decreased the
IVIS signal (photons/second) than GLIPR1- $\Delta$ TM alone did $(p=0.012)$ but docetaxel alone did not $(p=0.16)$ (Fig. 6a). However, the tumors that were treated with combination therapy had significantly lower wet weight than the tumors in the mice treated with docetaxel alone ( $p=$ $0.028)$ or GLIPR1- $\Delta$ TM alone $(p=0.0025)$ did (Fig. 6b). We collected lymph node samples from all mice and evaluated them for the presence of metastatic PCa cells as evidenced by cytokeratin 18 staining. Neither of the two 




agents significantly altered the emergence of metastasis, but combination therapy decreased the incidence of metastasis than control treatment did $(p=0.04)$ (Fig. 6c).

\section{Discussion}

In the present study we tested our hypothesis that GLIPR1- $\Delta \mathrm{TM}$ can synergize with docetaxel (one of the two chemotherapy agents approved for the treatment of $\mathrm{mCRPC}$ ) and whether the combination treatment can lead to greater cell death than treatment with docetaxel alone does. We showed that the combination of these two agents had synergistic effects on decreasing cell survival of $\mathrm{VCaP}$ and PC-3 cells. Apoptosis was the main mechanism for cell death, as demonstrated with DAPI staining and DNA fragmentation assay. Of note, the combination treatment appeared to lead to additive induction of JNK signaling since GLIPR1- $\triangle \mathrm{TM}$ was found to inhibit the
ERK1/2-c-Myc-CXCR4 resistance loop and consequently to suppress the inhibitory effects of ERK1/2 on JNK signaling, driving JNK signaling. Thus, the efficacy of the combination of these two agents is suggested to be mediated through synergistic apoptotic activity driven by dominant JNK signaling and downregulation of ERK1/ 2-c-Myc-CXCR4-mediated drug resistance and migration.

We further tested our hypothesis regarding the JNK hyperactivation via JNK inhibitor administration using two biological assays to assess the effect on survival and apoptosis and western blot to monitor the signaling changes. We found that the addition of the inhibitor to the combination treatment resulted in increased survival and reduced apoptosis compared to combination treatment alone in both PCa cell lines; whereas on Western blots we observed a marked reduction in JNK phosphorylation together with a concomitant increase in ERK1/2 
phosphorylation, and c-Myc and CXCR4 protein levels compared to combination treatment without inhibitor. We further tested the effect of CXCR4 downregulation on combination treatment to determine its role as a central component of the ERK1/2-c-Myc-stimulated resistance loop. In support of our hypothesis, we found that CXCR4 knockdown combined with the combination treatment further enhanced apoptosis and reduced the survival of the cells. This finding demonstrates the opposing biological effects of GLIPR1- $\triangle$ TM on c-MycCXCR4-mediated drug resistance and migration [17, 28]. In consideration of this mechanism we tested our hypothesis via migration assay and found that docetaxel and GLIPR1- $\Delta$ TM combination treatment resulted in significantly reduced numbers of migrated cells than docetaxel alone did, mimicking the result of docetaxel combined with CXCR4 inhibitor and supporting our hypothesis for a role for GLIPR1- $\triangle$ TM suppression of PCa cell migration.

To test our treatment combination effectiveness in vivo, we treated nude mice bearing $\mathrm{VCaP}$ orthotopic xenografts with docetaxel, GLIPR1- $\triangle T$ M, or both for 3 weeks. Combination treatment decreased IVIS signal than GLIPR1- $\triangle T M$ did and decreased significantly tumor weight than both single-agent treatments did. The finding that the incidence of lymph node metastasis was significantly lower in animals treated with the combination treatment than in control-treated animals is consistent with our in vitro data and may be related to the inhibition of the docetaxel-induced ERK1/2-CXCR4-c-Myc axis by GLIPR1- $\Delta$ TM.

\section{Conclusions}

The results of our study demonstrated that docetaxel and GLIPR1- $\triangle \mathrm{TM}$ combination treatment leads to increased JNK-mediated apoptosis compared to single agent treatment. These activities are accompanied by inhibition of ERK1/2-c-Myc-CXCR4 signaling, which results in derepression of JNK signaling, leading to maximal JNK-mediated apoptotic effects. In addition docetaxel and GLIPR1- $\triangle$ TM combination treatment may suppress migration through downregulation of the ERK1/2-c-MycCXCR4 drug resistance pathway and reduces metastatic potential in vivo. Based on our results, its conceivable that GLIPR1- $\triangle \mathrm{TM}$ (which is currently progressing toward clinical trials) or therapy agents that act through similar mechanisms may be used together with reduced dosage of docetaxel with potentially greater therapeutic efficacy than docetaxel alone, and with probably fewer adverse effects. It is also conceivable that docetaxel and GLIPR1- $\Delta$ TM combination treatment could possibly result in delay in developing docetaxel resistance. Further preclinical and clinical studies will be needed to develop GLIPR1- $\Delta$ TM therapy through clinical trials and to evaluate the safety and efficacy of this combination in patients with mCRPC.

\section{Methods}

\section{Cell lines and reagents}

The non-tumorigenic RWPE-1 cells (from the American Type Culture Collection) were grown in complete keratinocyte serum-free medium. PC-3 and VCaP prostate cancer cells were grown as described previously [26]. All cell lines were validated by short tandem repeat DNA fingerprinting with the AmpFISTR Identifier Kit (Applied Biosystems, Inc., Foster City, CA) at the Characterized Cell Line Core Facility of The University of Texas MD Anderson Cancer Center. Docetaxel and AMD3100, a CXCR4 inhibitor, were purchased from Sigma-Aldrich (St. Louis, MO). SP600125, a JNK inhibitor, was purchased from Santa Cruz.

\section{Purification of recombinant GLIPR1- $\Delta T M$}

GLIPR1- $\triangle \mathrm{TM}$ coding sequence was obtained from normal prostate tissue by RT-PCR using specific primers (forward: 5'CCCAAGCTTGCAAATATTTTG CCAGAT3', reverse: 5ATAGT TTAGCGGCCGCTCT GTTACGTGGATATAT3'). The PCR product was digested with restriction enzymes Hinlll and NotI and inserted into pSectag/ Hygro2 Hinlll and NotI sites to generate pSec-GLIPR1- $\triangle \mathrm{TM}$ as previously described [24, 26]. Conditioned medium from 293 Freestyle cells transfected with pSec-GLIPR1- $\triangle \mathrm{TM}$ was collected and centrifuged, and GLIPR1- $\triangle$ TM was purified using Ni-NTA agarose.

\section{Cell viability assay}

Cell viability was analyzed using an MTS CellTiter 96 Aqueous One Solution Cell Proliferation Assay (Promega, Madison, WI) according to the manufacturer's instructions as previously described [30]. After appropriate cell treatment (96-well assay plate) $20 \mu \mathrm{l}$ of CellTiter $96^{\circ}$ Aqueous One Solution Reagent were added into each well. The plate was intubated for $2 \mathrm{~h}$ at $37{ }^{\circ} \mathrm{C}$ in a humidified $5 \% \mathrm{CO}_{2}$ chamber. The absorbance at $490 \mathrm{~nm}$ was recorded using the 96-well plate reader.

\section{Apoptosis analysis}

Apoptotic nuclear morphology was evaluated with fluorescence microscopy after 4',6-diamidino-2-phenylindole (DAPI) staining $(2 \mu \mathrm{g} / \mathrm{ml})$. DNA fragmentation analysis was performed using Cell Death Detection ELISA (Roche Applied Science, Indianapolis, IN) according to the manufacturer's instructions. After the appropriate treatment, a cell suspension of $2 \times 10^{5}$ cells was collected, the cells were pelleted by centrifugation and the supernatant was discarded. $1 \mathrm{~mL}$ of PBS was added and the full volume of re-suspended cells was transferred to $4 \mathrm{~mL}$ of absolute ethanol at $-20{ }^{\circ} \mathrm{C}$ by pipetting the cell suspension slowly into the ethanol while vortexing at top speed. The cells were intubated in ethanol at $-20{ }^{\circ} \mathrm{C}$ for $5-15^{\circ} \mathrm{min}$. The ethanol was discarded and $5 \mathrm{~mL}$ of PBS at room 
temperature to rehydrate for $15 \mathrm{~min}$. The DAPI stock solution was diluted to $3 \mu \mathrm{M}$ in staining buffer (100 mM Tris, $\mathrm{pH}$ 7.4, $150 \mathrm{mM} \mathrm{NaCl}, 1 \mathrm{mM} \mathrm{CaCl}$, $0.5 \mathrm{mM} \mathrm{MgCl} 2,0.1 \%$ Nonidet P-40). After adding the solution the cell suspension was centrifuged and the supernatant was discarded. $1 \mathrm{~mL}$ of DAPI diluted in staining buffer was added and the cells were intubated for 15 min at room temperature. The cells' staining was analyzed by flow cytometry.

\section{DNA fragmentation assay}

DNA fragmentation assay was performed using a Cell Death Detection ELISA Kit (Roche, Mannheim, Germany) according to manufacturer's protocol as previously described [26]. The assay is a photometric enzymeimmunoassay for the qualitative and quantitative in vitro determination of cytoplasmic histone-associated DNA fragments (mono- and oligonucleosomes) after induced cell death.

\section{Isobologram analysis}

The effects of drug combinations were categorized as additive, synergistic, or antagonistic by isobologram analysis as previously described [31], and IC50 was used to determine the fixed ratio. A graph of equally effective dose pairs (isoboles) for a single effect level is presented. Specifically, a particular effect level of $50 \%$ of the maximum is selected, and doses of docetaxel and GLIPR1- $\triangle \mathrm{TM}$ (each alone) that give this effect are plotted as axial points in a Cartesian plot. The straight line connecting axial and vertical axes is the locus of points (dose pairs) that will produce this effect in a simply additive combination. This line of additivity allows a comparison with the actual dose pair that produces this effect level experimentally. An actual dose pair below the straight line attains this effect with lesser quantities and is super-additive (synergistic), while the dose pair denoted above the straight line means greater quantities are required and is therefore sub-additive.

\section{RNA interference}

Knockdown of CXCR4 was achieved by transient transfection of VCaP cells with a pool of CXCR4-specific siRNA (Invitrogen), and a pool of non-targeting siRNA (NCsi) (Invitrogen), as control, by using Lipofectamine RNAiMax transfection reagent (Invitrogen). VCaP cells were seeded at a density of $1.0 \times 10^{6}$ in six-well plates. Cells were transfected with $20 \mathrm{nM}$ CXCR4si or NCsi the following day. $24 \mathrm{~h}$ later cells were treated with DMSO or 1 and $2 \mathrm{nM}$ of docetaxel in Dulbecco modified Eagle medium (DMEM) containing $0.5 \%$ serum.

\section{Western blot analysis}

For evaluation of JNK and ERK1/2-c-Myc-CXCR4 signaling, PC-3 cells were treated for $24 \mathrm{~h}$ with RPMI- 1640 medium containing $0.1 \%$ serum and $\mathrm{VCaP}$ cells were treated for $24 \mathrm{~h}$ with Dulbecco modified Eagle medium (DMEM) containing $0.5 \%$ serum. Then, cells were treated with $10 \mu \mathrm{g} / \mathrm{ml}$ GLIPR1- $\Delta \mathrm{TM}$ for $1 \mathrm{~h}$ followed by the addition of $1 \mathrm{nM}$ docetaxel with or without $1 \mu \mathrm{M}$ SP600125 and lysates were collected 24 h later (VCaP cells) and $48 \mathrm{~h}$ later (PC-3 cells). Antibodies against GLIPR1- $\triangle$ TM (Myc-tag), phospho-JNK, JNK, phosphoERK1/2, ERK1/2, c-Myc, and CXCR4 were all purchased from Cell Signaling Technology (Danvers, MA), and antibody against GAPDH was purchased from Santa Cruz. When indicated, densitometric analysis was performed and quantification of integrated density was assessed using the NIS-Elements-AR software program (version 3.0; Nikon) followed by GAPDH normalization.

\section{Scratch assay}

PC-3 cells $\left(1 \times 10^{5}\right)$ and VCaP cells $\left(2 \times 10^{5}\right)$ were seeded in six-well plates and incubated overnight to achieve confluency. Next day, PC-3 cells were treated for $24 \mathrm{~h}$ with RPMI-1640 medium containing $0.1 \%$ serum, and $\mathrm{VCaP}$ cells were treated for $24 \mathrm{~h}$ with DMEM containing $0.5 \%$ serum. Then, the cell layer in each well was scratched using a plastic pipette tip, and cells were treated with $10 \mu \mathrm{g} / \mathrm{ml}$ GLIPR1- $\Delta \mathrm{TM}$ for $1 \mathrm{~h}$ followed by the addition of $1 \mathrm{nM}$ docetaxel for $24 \mathrm{~h}$. Cells were visualized under a microscope and photographed for the evaluation of migration.

\section{Tumor induction in mice, treatment protocols, and immunohistochemical analysis}

$\mathrm{VCaP}$ cells were transduced with lentivirus stably expressing luciferase. Aliquots of $2 \times 10^{6} \mathrm{VCaP}$-luciferase cells in $25 \mu \mathrm{l}$ of PBS were injected directly into the right lobe of the dorsolateral prostate in athymic nude male mice (Taconic Farms, Hudson, NY) to induce orthotopic tumors. The tumors were allowed to grow for 14 days before treatment. Mice were treated with $10 \mathrm{mg} / \mathrm{kg}$ docetaxel intraperitonealy weekly, $20 \mu \mathrm{g}$ of GLIPR1- $\Delta$ TM intraperitonealy three times per week, or both. The control group was treated with PBS. Tumor size was monitored by measuring the luminescence signal using the IVIS 200 imaging system (PerkinElmer, Wellesley, MA). After 3 weeks of treatment, tumor-bearing mice were sacrificed, and the tumors were collected and weighed. Lymph nodes were also collected, and antibody to cytokeratin 18 (DAKO, Carpinteria, CA; catalog no. M701029-2) was used for immunostaining on formalin-fixed paraffin-embedded lymph node tissues. All tissue sections were processed by using an avidin-biotin peroxidase complex kit (Vector Laboratories, Burlingame, CA) as previously described [32]. 


\section{Statistical analysis}

The results are presented as the mean \pm standard error from at least three independent experiments. Comparisons of groups were appropriately analyzed using the Student- $t$ test and the Mann-Whitney $U$ test. P values less than 0.05 were considered statistically significant and all tests were two-tailed. Fisher analysis was used to compare the incidences of lymph node metastasis in animal tissues. The isobologram study was used for the determination of synergy as described above.

\section{Additional file}

Additional file 1: Figure S1. Quantitative Data of Westerns Blots (relevant to Fig. 4a, b). A. VCaP cells densitomentry data B. PC-3 cells densitometry data. Figure S2 Quantitative data of Western Blots on 2 different CXCR4siRNAs for validation and determination of their effect size (relevant to Fig. 5a). A. CXCR4si7 is statistically significant in inhibiting CXCR4 protein expression than NCsi is $(p<0.001)$ and CXCR4si8 is $(p=0.002)$ in VCaP cells. B. CXCR4si7 is statistically significant in inhibiting CXCR4 protein expression than NCsi is $(p<0.001)$ and CXCR4si8 is $(p=0.01)$ in PC-3 cells.

\section{Abbreviations}

JNK: c- Jun NH2-terminal kinase; ROS: Reactive oxygen species; AR: Androgen receptor; $\mathrm{MCRPC}$ : Metastatic castrate resistant prostate cancer; GLIPR1: Gene encoding the human glioma pathogenesis-related protein 1; ERK1/2: Extracellular signal-regulated kinase1/2; CXCR4: C-X-C chemokine receptor type 4 .

\section{Competing interests}

The data included in this manuscript are relevant to intellectual property that has been licensed by Baylor College of Medicine to Progression Therapeutics, Inc., a private biotechnology start-up company. T.C. Thompson is an inventor of record on patents that are included in this licensing agreement.

\section{Authors' contributions}

TCT, SKA, TK and SKU conceived and designed the study. TCT, SKA and TK wrote the paper. SKA, TK, SKU, and JW performed MTS, DNA fragmentation and isobologram studies. TK and SKA performed Western blot analysis. TK, SKA and LL performed scratch assay. GY performed cytokeratin staining. TH, SP, AG and RT designed and conducted the xenograft model experiment. All authors contributed, read and approved the final manuscript.

\section{Funding}

This work was supported in part by National Cancer Institute grant R0150588 (to T.C.T.); National Cancer Institute grant P50140388, the Prostate Cancer Specialized Program of Research Excellence at The University of Texas MD Anderson Cancer Center; the NIH through MD Anderson's Cancer Center Support Grant, CA16672; DOD grant PC093932; and Tony's Prostate Cancer Research Foundation.

\begin{abstract}
Author details
'Department of Genitourinary Medical Oncology - Research, Unit 18-3, The University of Texas MD Anderson Cancer Center, 1515 Holcombe Boulevard, Houston, TX, USA. ²Department of Urology, Kitasato University School of Medicine, Sagamihara, Kanagawa, Japan. ${ }^{3}$ Department of Thoracic \& Cardio Surgery, The University of Texas MD Anderson Cancer Center, Houston, TX, USA. ${ }^{4}$ Department of Urology, Thomas Jefferson University Hospital, Philadelphia, PA, USA.
\end{abstract}

Received: 27 February 2015 Accepted: 29 May 2015

Published online: 19 June 2015

\section{References}

1. Ryan CJ, Smith MR, de Bono JS, Molina A, Logothetis CJ, de Souza P, et al. Abiraterone in metastatic prostate cancer without previous chemotherapy. N Engl J Med. 2013;368:138-48.
2. Scher HI, Fizazi K, Saad F, Taplin ME, Sternberg CN, Miller K, et al. Increased survival with enzalutamide in prostate cancer after chemotherapy. N Engl J Med. 2012;367:1187-97.

3. Tannock IF, de Wit R, Berry WR, Horti J, Pluzanska A, Chi KN, et al. Docetaxel plus prednisone or mitoxantrone plus prednisone for advanced prostate cancer. N Engl J Med. 2004;351(15):1502-12.

4. de Bono JS, Oudard S, Ozguroglu M, Hansen S, Machiels JP. Prednisone plus cabazitaxel or mitoxantrone for metastatic castration-resistant prostate cancer progressing after docetaxel treatment: a randomised open-label trial. Lancet. 2010;376(9747):1147-54.

5. van Soest RJ, de Morrée ES, Shen L, Tannock IF, Eisenberger MA, de Wit R. Initial Biopsy Gleason Score as a Predictive Marker for Survival Benefit in Patients with Castration-resistant Prostate Cancer Treated with Docetaxel: Data from the TAX327 Study. Eur Urol. 2014;66(2):330-6.

6. Pienta KJ. Preclinical mechanisms of action of docetaxel and docetaxel combinations in prostate cancer. Semin Oncol. 2001;28(4 Suppl 15):3-7.

7. Haldar S, Basu A, Croce CM. BCl2 is the guardian of microtubule integrity. Cancer Res. 1997;57(2):229-33.

8. Haldar S, Chintapalli J, Croce CM. Taxol induces bcl-2 phosphorylation and death of prostate cancer cells. Cancer Res. 1996;56(6):1253-5.

9. Mhaidat NM, Zhang XD, Jiang CC, Hersey P. Docetaxel-induced apoptosis of human melanoma is mediated by activation of c-Jun NH2-terminal kinase and inhibited by the mitogen-activated protein kinase extracellular signal-regulated kinase 1/2 pathway. Clin Cancer Res. 2007;13(4):1308-14.

10. Rabi T, Bishayee A. d -Limonene sensitizes docetaxel-induced cytotoxicity in human prostate cancer cells: Generation of reactive oxygen species and induction of apoptosis. J Carcinog. 2009;8:9.

11. Mhaidat NM, Thorne RF, Zhang XD, Hersey P. Regulation of docetaxel-induced apoptosis of human melanoma cells by different isoforms of protein kinase $C$. Mol Cancer Res. 2007:5(10):1073-81.

12. Xia Z, Dickens M, Raingeaud J, Davis RJ, Greenberg ME. Opposing effects of ERK and JNK-p38 MAP kinases on apoptosis. Science. 1995;270(5240):1326-31.

13. Shen YH, Godlewski J, Zhu J, Sathyanarayana P, Leaner V, Birrer MJ. Crosstalk between JNK/SAPK and ERK/MAPK pathways: sustained activation of JNK blocks ERK activation by mitogenic factors. J Biol Chem. 2003;278(29):26715-21. Epub 2003 May 8.

14. Monick MM, Powers LS, Gross TJ, Flaherty DM, Barrett CW, Hunninghake GW. Active ERK contributes to protein translation by preventing JNK-dependent inhibition of protein phosphatase 1. J Immunol. 2006;177(3):1636-45.

15. Nordström E, Fisone G, Kristensson K. Opposing effects of ERK and p38-JNK MAP kinase pathways on formation of prions in GT1-1 cells. FASEB J. 2009;23(2):613-22.

16. Leonetti C, Biroccio A, D'Angelo C, Semple SC, Scarsella M, Zupi G. Therapeutic integration of c-myc and bcl-2 antisense molecules with docetaxel in a preclinical model of hormone-refractory prostate cancer. Prostate. 2007;67(13):1475-85.

17. Hatano K, Yamaguchi S, Nimura K, Murakami K, Nagahara A, Fujita K, et al. Residual prostate cancer cells after docetaxel therapy increase the tumorigenic potential via constitutive signaling of CXCR4, ERK1/2 and c-Myc. Mol Cancer Res. 2013;11(9):1088-100.

18. Pezaro CJ, Omlin AG, Altavilla A, Lorente D, Ferraldeschi R, Bianchini D, et al. Activity of Cabazitaxel in Castration-resistant Prostate Cancer Progressing After Docetaxel and Next-generation Endocrine Agents. Eur Urol. 2014;66(3):459-65.

19. Sinibaldi VJ. Docetaxel treatment in the elderly patient with hormone refractory prostate cancer. Clin Interv Aging. 2007;2(4):555-60.

20. Araujo JC, Trudel GC, Saad F, Armstrong AJ, Yu EY, Bellmunt J, et al. Docetaxe and dasatinib or placebo in men with metastatic castration-resistant prostate cancer (READY): a randomised, double-blind phase 3 trial. Lancet Oncol. 2013;14(13):1307-16. Epub 2013 Nov 8.

21. Fizazi KS, Higano CS, Nelson JB, Gleave M, Miller K, Morris T, et al. Phase III, randomized, placebo-controlled study of docetaxel in combination with zibotentan in patients with metastatic castration-resistant prostate cancer. J Clin Oncol. 2013;31(14):1740-7.

22. Ren C, Li L, Yang G, Timme TL, Goltsov A, Ren C, et al. RTVP-1, a tumor suppressor inactivated by methylation in prostate cancer. Cancer Res. 2004;64(3):969-76.

23. Ren C, Li L, Goltsov AA, Timme TL, Tahir SA, Wang J, et al. mRTVP-1, a novel p53 target gene with proapoptotic activities. Mol Cell Biol. 2002;22(10):3345-57. 
24. Li L, Abdel Fattah E, Cao G, Ren C, Yang G, Goltsov AA, et al. Glioma pathogenesis-related protein 1 exerts tumor suppressor activities through proapoptotic reactive oxygen species-c-Jun-NH2 kinase signaling. Cancer Res. 2008;68(2):434-43.

25. Li L, Ren C, Yang G, Fattah EA, Goltsov AA, Kim SM, et al. GLIPR1 suppresses prostate cancer development through targeted oncoprotein destruction. Cancer Res. 2011;71(24):7694-704.

26. Karantanos T, Tanimoto R, Edamura K, Hirayama T, Yang G, Golstov AA, et al. Systemic GLIPR1- $\triangle$ TM protein as a novel therapeutic approach for prostate cancer. Int J Cancer. 2014;134(8):2003-13.

27. Bennett BL, Sasaki DT, Murray BW, O'Leary EC, Sakata ST, Xu W, et al. SP600125, an anthrapyrazolone inhibitor of Jun N-terminal kinase. Proc Natl Acad Sci U S A. 2001:98(24):13681-6.

28. Singh S, Singh UP, Grizzle WE, Lillard Jr JW. CXCL12-CXCR4 interactions modulate prostate cancer cell migration, metalloproteinase expression and invasion. Lab Invest. 2004;84(12):1666-76.

29. Domanska UM, Timmer-Bosscha H, Nagengast WB, Oude Munnink TH, Kruizinga RC, Ananias HJ, et al. CXCR4 inhibition with AMD3100 sensitizes prostate cancer to docetaxel chemotherapy. Neoplasia. 2012;14(8):709-18.

30. Tabata K, Kurosaka S, Watanabe M, Edamura K, Satoh T, Yang G, et al. Tumor growth and metastasis suppression by Glipr1 gene-modified macrophages in a metastatic prostate cancer model. Gene Ther. 2011;10:969-78.

31. Fivelman QL, Adagu IS, Warhurst DC. Modified fixed-ratio isobologram method for studying in vitro interactions between atovaquone and proguanil or dihydroartemisinin against drug-resistant strains of Plasmodium falciparum. Antimicrob Agents Chemother. 2004;48:4097-102.

32. Yang G, Goltsov AA, Ren C, Kurosaka S, Edamura K, Logothetis R, et al. Caveolin-1 upregulation contributes to c-Myc-induced high-grade prostatic intraepithelial neoplasia and prostate cancer. Mol Cancer Res. 2012;10(2):218-29.

\section{Submit your next manuscript to BioMed Central and take full advantage of:}

- Convenient online submission

- Thorough peer review

- No space constraints or color figure charges

- Immediate publication on acceptance

- Inclusion in PubMed, CAS, Scopus and Google Scholar

- Research which is freely available for redistribution 